\title{
Stereocontrolled annulations of indolo[2,3-a]quinolizidine-derived lactams with a silylated Nazarov reagent. Access to allo and epiallo yohimbine-type derivatives
}

\author{
Federica Arioli, ${ }^{[a]}$ Maria Pérez, ${ }^{[a]}$ Celeste Are,${ }^{[a]}$ Carolina Estarellas, ${ }^{[b]}$ F. Javier Luque, ${ }^{* b]}$ Joan Bosch, ${ }^{[a]}$ \\ and Mercedes Amat ${ }^{\star[a]}$
}

\begin{abstract}
The facial selectivity of double Michael addition reactions of the silylated Nazarov reagent 4 to unsaturated indolo[2,3a]quinolizidine lactams 3 is studied. Pentacyclic $3-\mathrm{H} / 15-\mathrm{H}$ trans adducts 5 are generated from $N_{\text {ind }}$-unsubstituted lactams, but the corresponding cis isomers 6 are formed when the indole nitrogen bears a Boc substituent. This reversal in the facial selectivity of the annulation has been rationalized by means of theoretical calculations, which indicate that the initial nucleophilic attack under stereoelectronic control is hampered by the presence of the bulky Boc group. The synthetic usefulness of the pentacyclic Nazarovderived adducts is demonstrated by their conversion to allo and epiallo yohimbine-type targets.
\end{abstract}

\section{Introduction}

The corynantheine-heteroyohimbine ${ }^{[1]}$ and yohimbine ${ }^{[2]}$ alkaloids constitute two of the largest subgroups of indole alkaloids. They are characterized by a tetracyclic indolo[2,3-a]quinolizidine system, which is fused to an additional six-membered oxygenated ring in the heteroyohimbine-type and to a cyclohexane ring in yohimbine-type alkaloids (Figure 1).

From the stereochemical standpoint, these alkaloids can be subdivided into four general series, depending on the relative configuration of the $3-\mathrm{H}, 15-\mathrm{H}$, and $20-\mathrm{H}$ stereocenters. ${ }^{[3,4]}$ The stereochemical diversity makes these alkaloids attractive targets for the development of stereoselective synthetic methodologies. In this context, a crucial aspect is the control of the cis or trans $3-\mathrm{H} / 15-\mathrm{H}$ relative stereochemistry, which can be accomplished by stereocontrolled conjugate addition to an unsaturated indoloquinolizidine lactam. Thus, Allin et al. ${ }^{[5]}$ and Martin and

[a] F. Arioli, Dr. M. Pérez, C. Are, Prof. M. Amat, Prof. J. Bosch Laboratory of Organic Chemistry

Faculty of Pharmacy and Institute of Biomedicine (IBUB)

University of Barcelona, 08028 (Spain)

E-mail: amat@ub.edu

[b] Dr. C. Estarellas, Prof. F. J. Luque,

Department of Physical Chemistry

Faculty of Pharmacy and Institute of Biomedicine (IBUB)

University of Barcelona, 08028 (Spain)

Supporting information for this article is given via a link at the end of the document.((Please delete this text if not appropriate)

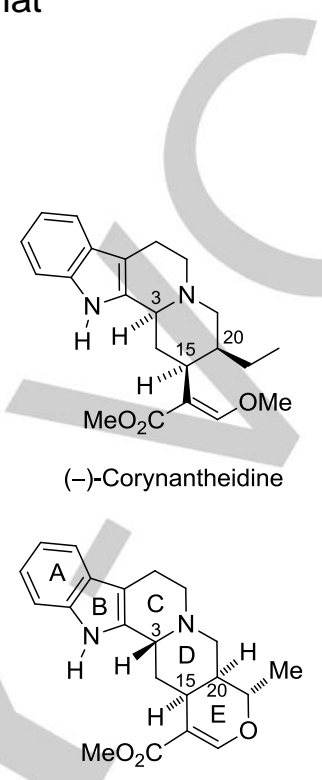

(-)-Akuammigine

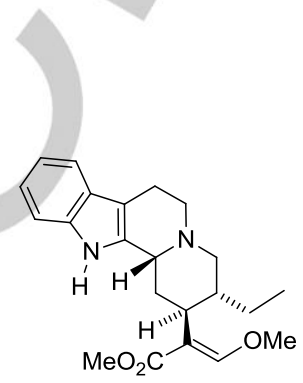

(+)-Hirsutine

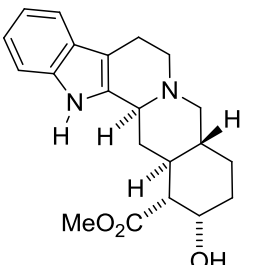

(+)-Yohimbine $\mathrm{O} H$

Figure 1. Alkaloids of the corynantheine-heteroyohimbine and yohimbine groups.

coworkers $^{[6]}$ independently reported that the conjugate addition of the lithium enolate derived from methyl or ethyl 1,3-dithiolane2-carboxylate to the $N_{\text {ind }}$-unsubstituted lactam 1a affords the trans $3-\mathrm{H} / 15-\mathrm{H}$ adduct 2a with high facial selectivity ( $\mathrm{Si}$ face). In contrast, a similar reaction from the $\mathrm{N}$-Boc protected indole $\mathbf{1 b}$ takes place with opposite facial selectivity to give the cis $3-\mathrm{H} / 15$ $\mathrm{H}$ adduct $\mathbf{2} \mathbf{b}$ (Scheme 1$)$.

A 3-H/15- $\mathrm{H}$ trans stereochemistry was also obtained in a variety of conjugate addition reactions to $N_{\text {ind }}$-unsubstituted ${ }^{[6-9]}$

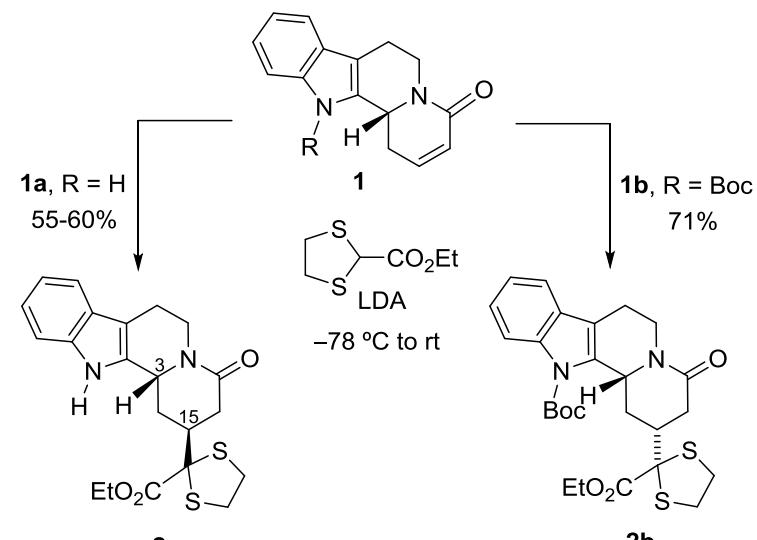

$2 a$

$2 b$ 
and $N_{\text {ind }}$-benzyl ${ }^{[5 a, 10,11]}$ indoloquinolizidine lactams using 2-lithio$\mathrm{N}, \mathrm{N}$-dimethylacetamide, ${ }^{[7]}$ organocuprates, ${ }^{\left[{ }^{[5,6,8]}\right.}$ the enolate of dimethyl malonate, ${ }^{[5 a, 9,10]}$ 2-lithio-1,3-dithiane, ${ }^{[5 a]}$ or an ynamine ${ }^{[11]}$ as nucleophiles. ${ }^{[12]}$

The Si facial selectivity of the above conjugate additions can be rationalized by considering that the nucleophilic attack occurs under stereoelectronic control, ${ }^{[13]}$ via a chair-like transition state, axial to the electrophilic carbon of the conjugated double bond and, consequently, cis with respect to the axial $3-\mathrm{H}$ substituent. ${ }^{[14]}$ The reversal of the diastereoselectivity in the addition to the $N_{\text {ind }}$-Boc lactam $\mathbf{1 b}$ has been attributed ${ }^{[6]}$ to steric factors arising from the bulky tert-butoxycarbonyl protecting group.

In this paper, we report stereoselective base-catalyzed double Michael addition reactions of unsaturated $\beta$-oxoester 4 with unsaturated indolo[2,3-a]quinolizidine lactams $\mathbf{3}$. Theoretical calculations were used to rationalize the dramatic reversal in the facial selectivity of the annulation observed when the indole nitrogen bears a protecting tert-butoxycarbonyl group. The synthetic usefulness of the resulting pentacyclic adducts is demonstrated by their conversion to allo and epiallo yohimbinetype targets, such as the proposed structures for nitraraine and related alkaloids and their corresponding trans 3-H/15- $\mathrm{H}$ derivatives.

\section{Results and Discussion}

\section{Double Michael addition reactions of the silylated Nazarov reagent 4}

Recently, we have observed ${ }^{[15]}$ the crucial role of the $N_{\text {ind }}$-Boc protecting group in reversing the facial selectivity of basecatalyzed double Michael addition reactions of unsaturated $\beta$ oxoester 4, a modified Nazarov reagent, ${ }^{[16]}$ with unsaturated indoloquinolizidine lactams. Starting from the enantiopure $N_{\text {ind }}-\mathrm{H}$ lactam $3 \mathbf{a}$, the trans $3-\mathrm{H} / 15-\mathrm{H}$ pentacyclic yohimbine-type derivative $\mathbf{5 a}$ was stereoselectively formed (Table 1, entry 1), whereas under similar reaction conditions $N_{\text {ind }}$-Boc lactam $\mathbf{3 b}$ led to the $3-\mathrm{H} / 15-\mathrm{H}$ cis pentacycle $\mathbf{6 b}$ (entry 2 ). These reactions were carried out in the presence of cesium carbonate, the most commonly used base for the generation of the enolate salt of Nazarov reagents. ${ }^{[1]}$

Similar differences of stereoselectivity were observed in the

Table 1. Double Michael addition reactions of the silylated Nazarov reagent $\mathbf{4}$ with unsaturated indolo[2,3-a]quinolizidine lactams 3.
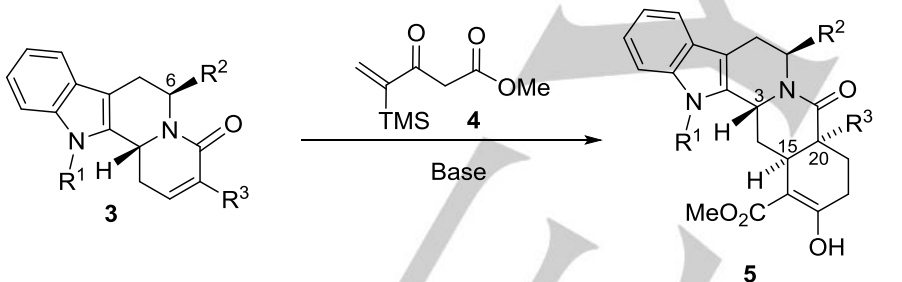

5

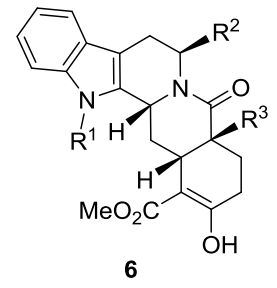

\begin{tabular}{|c|c|c|c|c|c|c|c|}
\hline Entry & Substrate ${ }^{[a]}$ & $\mathrm{R}^{1}$ & $\mathrm{R}^{2}$ & $\mathrm{R}^{3}$ & Base & Yield [\%] & Products (ratio) \\
\hline 1 & $3 a$ & $\mathrm{H}$ & $\mathrm{CH}_{2} \mathrm{OH}$ & $\mathrm{CO}_{2} \mathrm{Bn}$ & $\mathrm{Cs}_{2} \mathrm{CO}_{3}$ & 47 & $5 a^{[b]}$ \\
\hline 2 & $3 b$ & Boc & $\mathrm{CH}_{2} \mathrm{OBoc}$ & $\mathrm{CO}_{2} \mathrm{Bn}$ & $\mathrm{Cs}_{2} \mathrm{CO}_{3}$ & 75 & $6 b$ \\
\hline 3 & $3 c$ & $\mathrm{H}$ & $\mathrm{H}$ & $\mathrm{CO}_{2} \mathrm{Bn}$ & $\mathrm{Cs}_{2} \mathrm{CO}_{3}$ & 50 & $5 c+6 c(5: 1)$ \\
\hline 4 & $3 c$ & $\mathrm{H}$ & $\mathrm{H}$ & $\mathrm{CO}_{2} \mathrm{Bn}$ & DBU & 53 & $5 c+6 c(5: 1)$ \\
\hline 5 & $3 d$ & Boc & $\mathrm{H}$ & $\mathrm{CO}_{2} \mathrm{Bn}$ & $\mathrm{Cs}_{2} \mathrm{CO}_{3}$ & 71 & $6 d$ \\
\hline 6 & $3 d$ & Boc & $\mathrm{H}$ & $\mathrm{CO}_{2} \mathrm{Bn}$ & DBU & 64 & $6 d$ \\
\hline 7 & $3 e$ & Boc & $\mathrm{CH}_{2} \mathrm{OBoc}$ & $\mathrm{SO}_{2} \mathrm{C}_{6} \mathrm{H}_{5}$ & $\mathrm{Cs}_{2} \mathrm{CO}_{3}$ & 64 & $5 e+6 e(1: 2)$ \\
\hline 8 & $3 e$ & Boc & $\mathrm{CH}_{2} \mathrm{OBoC}$ & $\mathrm{SO}_{2} \mathrm{C}_{6} \mathrm{H}_{5}$ & DBU & 52 & $6 e$ \\
\hline 9 & $3 f$ & Boc & $\mathrm{H}$ & $\mathrm{SO}_{2} \mathrm{C}_{6} \mathrm{H}_{5}$ & $\mathrm{Cs}_{2} \mathrm{CO}_{3}$ & 83 & $5 \mathbf{f}+\mathbf{6 f}(1: 1)$ \\
\hline 10 & $3 f$ & Boc & $\mathrm{H}$ & $\mathrm{SO}_{2} \mathrm{C}_{6} \mathrm{H}_{5}$ & DBU & 60 & $6 f$ \\
\hline 11 & $3 g$ & $\mathrm{H}$ & $\mathrm{H}$ & $\mathrm{SO}_{2} \mathrm{C}_{6} \mathrm{H}_{5}$ & $\mathrm{Cs}_{2} \mathrm{CO}_{3}$ & 30 & $5 \mathrm{~g}$ \\
\hline 12 & $3 \mathrm{~h}$ & Ts & $\mathrm{H}$ & $\mathrm{SO}_{2} \mathrm{C}_{6} \mathrm{H}_{5}$ & $\mathrm{Cs}_{2} \mathrm{CO}_{3}$ & 67 & $5 \mathbf{h}^{[\mathrm{b}]}$ \\
\hline
\end{tabular}

[a] Compounds $\mathbf{3 c}, \mathbf{3} \mathbf{d}$, and $\mathbf{3} \mathbf{f}-\mathbf{h}$ are racemic mixtures. Compounds $\mathbf{3} \mathbf{a}, \mathbf{3 b}$, and $\mathbf{3 e}$ are optically active materials. [b] Minor amounts of the 15,20 diastereoisomer were detected. 
reactions of $\mathbf{4}$ with $N_{\text {ind }}$-unsubstituted indoloquinolizidine $3 c^{[18]}$ (entries 3 and 4 ) and its $N_{\text {ind }}$-Boc derivative $3 \mathbf{d}^{[19]}$ (entries 5 and $6)$, which lack the C-6 chain, using either $\mathrm{Cs}_{2} \mathrm{CO}_{3}$ or DBU (1,8diazabicyclo[5.4.0]undec-7-ene) as the bases. ${ }^{[20]}$ Starting from lactam $3 \mathrm{c}$, the $3-\mathrm{H} / 15-\mathrm{H}$ trans derivative $5 \mathrm{c}$ was formed as the major product, whereas the $N_{\text {ind }}$-Boc lactam $3 \mathbf{d}$ stereoselectively afforded the cis isomer $\mathbf{6} \mathbf{d}$.

The above reactions involve the generation of the C-15 stereocenter by an initial nucleophilic attack of the Nazarov enolate, and the subsequent stereoselective closure of ring $E^{[21]}$ by a second Michael addition in which the initially formed 1,3dicarbonyl enolate acts as the nucleophile and the conjugated double bond of the silylated Nazarov reagent is the Michael acceptor. ${ }^{[22]}$ Additionally, the TMS group, at the $\alpha$ position of a carbonyl group, undergoes in situ protodesilylation.

Interestingly, the silylated Nazarov reagent $\mathbf{4}$ can be envisaged as a synthetic equivalent of the original Nazarov reagent. ${ }^{[16]}$ It avoids the polymerization problems associated with the latter when operating under basic conditions, ${ }^{[23]}$ being able to participate in base-promoted annulations with $\alpha, \beta$-unsaturated carbonyl compounds.

Although the procedure provided stereocontrolled access to pentacyclic $3-\mathrm{H} / 15-\mathrm{H} / 20-\mathrm{R}^{3}$ trans/cis and cis/cis derivatives, the removal of the benzyloxycarbonyl substituent from $\mathbf{6 b}$ by hydrogenolysis, followed by thermal decarboxylation, proved to be non-stereoselective, leading to a 1:1 mixture of D/E cis- and trans-fused pentacycles $\mathbf{8}$ and $\mathbf{9}$, respectively (Scheme 2 ).
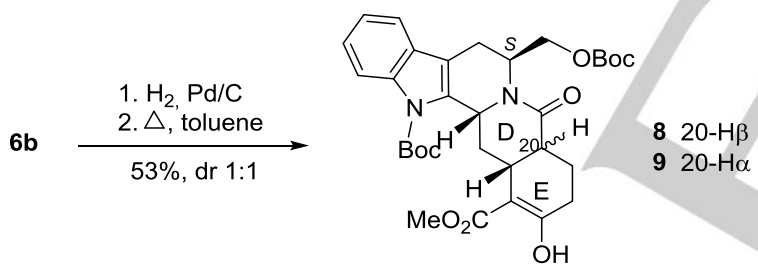

Scheme 2. Removal of the benzyloxycarbonyl substituent.

Taking into account that the success of double Michael addition reactions using Nazarov reagents depends upon the presence of an additional electron-withdrawing group in the starting Michael acceptor, ${ }^{[24]}$ to test new annulations with the silylated reagent 4 we selected enantiopure lactam $3 e,{ }^{[15]}$ which bears an activating and easily removable phenylsulfonyl group $\alpha$ to the lactam carbonyl. ${ }^{[25,26]}$ Although the reaction of $\mathbf{4}$ with unsaturated $\mathrm{N}$-Boc lactam $3 \mathrm{e}$ took place with only moderate facial selectivity under the usual $\mathrm{Cs}_{2} \mathrm{CO}_{3}$ basic conditions $(5 \mathrm{e} / 6 \mathrm{e}$ ratio, 1:2; Table 1, entry 7), ${ }^{[27]}$ the expected $3-\mathrm{H} / 15-\mathrm{H}$ cis isomer $6 e$ was stereoselectively formed when $\mathrm{DBU}^{[20]}$ was used as the base (entry 8)

Gratifyingly, the dephenylsulfonylation of the pentacyclic adducts $5 \mathbf{e}$ and $6 \mathbf{e}$ using $\mathrm{Na} / \mathrm{Hg}$ at $-78{ }^{\circ} \mathrm{C}$ was completely stereoselective, leading to the respective epiallo- and allo-type pentacycles 10 and 8 (Scheme 3).

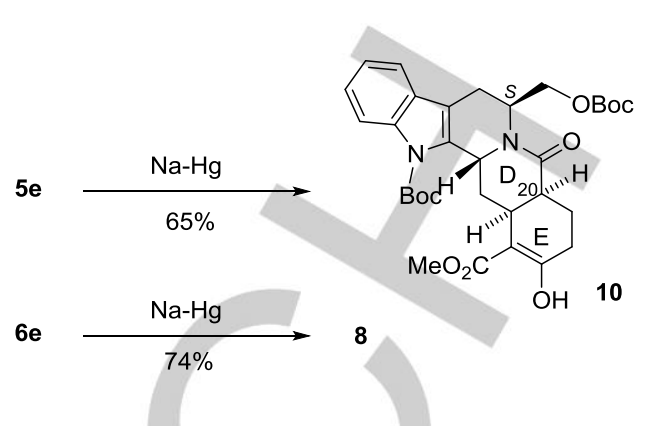

Scheme 3. Stereoselective removal of the phenylsulfonyl substituent.

As already observed in the above lactams bearing the activating benzyloxycarbonyl substituent, the absence of the $\mathrm{CH}_{2} \mathrm{OBoc}$ group in the phenylsulfonyl-substituted series did not modify the stereoselectivity of the double Michael annulations. Thus, as in the phenylsulfonyl-substituted lactam $\mathbf{3 e}$, the $\mathrm{Cs}_{2} \mathrm{CO}_{3}$-promoted annulation of lactam $3 \mathrm{fi}^{[28]}$ with $\mathbf{4}$ was not stereoselective (entry 9), ${ }^{[27]}$ but under DBU basic conditions $N_{\text {ind }}{ }^{-}$ Boc pentacycle 6f, with the expected $3-\mathrm{H} / 15-\mathrm{H}$ cis stereochemistry, was stereoselectively obtained (entry 10). In contrast, as could be expected for an $N_{\text {ind }}-\mathrm{H}$ derivative, lactam $\mathbf{3} \mathbf{g}^{[18]}$ afforded a $3-\mathrm{H} / 15-\mathrm{H}$ trans pentacycle, $\mathbf{5 g}$, although the yield was low due to purification problems (entry 11).

To further investigate the influence of the indole nitrogen substituent on the facial selectivity of annulations with Nazarov reagent 4, we also used the $N_{\text {ind }}$-tosyl indoloquinolizidine lactam $3 \mathbf{h} .{ }^{[29]}$ The reaction was highly stereoselective when $\mathrm{Cs}_{2} \mathrm{CO}_{3}$ was employed as the base, leading to the $3-\mathrm{H} / 15-\mathrm{H}$ trans pentacycle 5 h (entry 12).

The results summarized in Table 1 are in good agreement with previous studies ${ }^{[5,6]}$ for the reversal of the facial selectivity of conjugate addition reactions on unsaturated indoloquinolizidine lactams caused by the bulky Boc group on the indole nitrogen. When the appropriate base is chosen, $N_{\text {ind }}-\mathrm{H}$ and $N_{\text {ind }}-\mathrm{Ts}$ lactams react with the silylated Nazarov reagent 4 to stereoselectively give yohimbine-type pentacycles $\mathbf{5}$, with a 3 $\mathrm{H} / 15-\mathrm{H}$ trans relationship, whereas $N_{\text {ind }}$-Boc lactams lead to 3$\mathrm{H} / 15-\mathrm{H}$ cis derivatives 6 . Taking into account the accessibility of enantiopure tryptophanol-derived indoloquinolizidine lactams and that the hydroxymethyl substituent of these lactams can be easily removed, ${ }^{[30]}$ the methodology here developed can provide access to pentacyclic derivatives both in the racemic series and in enantiopure form.

\section{Theoretical calculations}

To understand the origin of the $3-\mathrm{H} / 15-\mathrm{H}$ cis and trans stereochemistry, Density Functional Theory (DFT) calculations were performed to locate the transition state for the addition of reagent 4 (after replacement of TMS by a methyl group) to compounds 3 , considering both the $N_{\text {ind }}$-unsubstituted indoloquinolizidine and its $N_{\text {ind }}$-Boc derivative. Furthermore, $\mathrm{R}^{3}$ was modelled with either a hydrogen atom or with 
methoxycarbonyl (chosen to mimic the benzyloxycarbonyl substituent). Finally, $\mathrm{R}^{2}$ was modelled with a hydrogen atom due to the apparent lack of influence of this substituent on the stereoselectivity of the final product (see Table 1), although the effect of the C-6 hydroxymethyl group on the conformational preferences was explored. DFT calculations were performed using the M062X ${ }^{[31]}$ method and the $6-31 \mathrm{G}(\mathrm{d})^{[32]}$ basis set. The geometries were fully optimized in the gas phase. Solvent effects $\left(\mathrm{CH}_{2} \mathrm{Cl}_{2}\right.$ and THF) were accounted for by means of single-point calculations performed at the B3LYP/6-31G(d) level ${ }^{[33]}$ in conjunction with the $\mathrm{SMD}^{[34]}$ continuum model. Additionally, solvation calculations at the M062X/6-31G(d) level of theory were also performed, but no significant differences were found between solvation free energies derived from B3LYP and M062X calculations (see Tables S3 and S4 in Supporting Information).

In a preliminary step, we examined the conformational preferences of compounds 3 . For the $N_{\text {ind }}$-unsubstituted indoloquinolizidine, three conformations were identified. In two of them (denoted I and II; Figure 2) ring D is slightly twisted away from the molecular plane of the indole ring. These conformations differ in the relative position of the carbon atom at position 6 , so that it is shifted above and below the plane of the indole in conformations I and II, respectively. In the third conformation (denoted III), ring $\mathrm{D}$ is bent, adopting a roughly orthogonal arrangement to the fused tricyclic system. Both in the gas phase and in solution, conformation I was found to be the most favoured, with a population larger than $97 \%$ at the M062X level (Table 2).
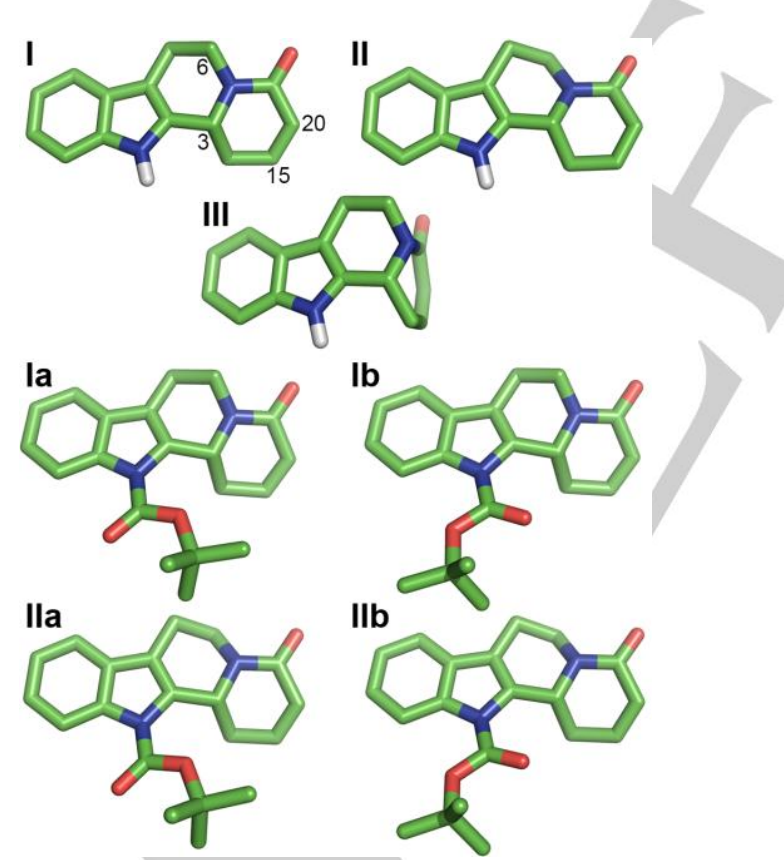

Figure 2. Representation of the conformational states determined for unsaturated indoloquinolizidines.

For the $N_{\text {ind }}$-Boc derivative, only conformations I and II were located, each encompassing two distinct orientations of the Boc moiety (denoted $\mathbf{a}$ and $\mathbf{b}$ in Figure 2). The results in Table 2 clearly show that conformation $\mathbf{I}$ is the major species (by more than $99 \%$ ) in the gas phase and in solution, with a ratio close to $2: 1$ between conformations $\mathbf{l a}$ and $\mathbf{I b}$. It is worth noting that conformation I was also found in the X-ray structure of the $N_{\text {ind }}{ }^{-}$ Boc derivative of compound 3 with $\mathrm{R}^{2}=\mathrm{R}^{3}=\mathrm{H}^{[6]}$ Finally, the preference for conformation I of both $N_{\text {ind }}-\mathrm{H}$ and $N_{\text {ind }}-$ Boc unsaturated indoloquinolizidines is also supported by the results obtained from single-point calculations at the MP2/aug-cc-pVDZ level (see Table 2).

Table 2. Relative free energy $(\mathrm{kcal} / \mathrm{mol})$ of the conformational states of the $N_{\text {ind }}$-unsubstituted indoloquinolizidines and their $N_{\text {ind }}$-Boc derivatives at the M062X/6-31G(d) level.

\begin{tabular}{|l|l|l|l|}
\hline Conformation & $\mathrm{Gas}^{[\mathrm{a}]}$ & $\mathrm{THF}$ & $\mathrm{CH}_{2} \mathrm{Cl}_{2}$ \\
\hline \multicolumn{4}{|c|}{$N_{\text {ind }}-\mathrm{H}, \mathrm{R}^{2}=\mathrm{R}^{3}=\mathrm{H}$} \\
\hline I & $0.0(0.0)$ & 0.0 & 0.0 \\
\hline II & $3.7(3.9)$ & 3.5 & 3.5 \\
\hline III & $2.7(1.1)$ & 2.5 & 2.4 \\
\hline \multicolumn{4}{|c|}{$N_{\text {ind }}-\mathrm{H}, \mathrm{R}^{2}=\mathrm{CH}_{2} \mathrm{OH}, \mathrm{R}^{3}=\mathrm{C}(\mathrm{O}) \mathrm{OM}$} \\
\hline I & 0.0 & 0.0 & 0.0 \\
\hline II & 7.1 & 6.0 & 6.1 \\
\hline III & 6.4 & 5.6 & 5.3 \\
\hline \multicolumn{5}{|l|}{$N_{\text {ind- }}-\mathrm{Boc}^{2} \mathrm{R}^{2}=\mathrm{R}^{3}=\mathrm{H}$} \\
\hline Ia & $0.0(0.0)$ & 0.0 & 0.0 \\
\hline Ib & $0.2(1.1)$ & 0.5 & 0.5 \\
\hline Ila & $5.9(5.7)$ & 5.8 & 5.7 \\
\hline IIb & $6.2(7.0)$ & 6.4 & 6.3 \\
\hline \multicolumn{5}{|l|}{$N_{\text {ind }}-\mathrm{Boc}, \mathrm{R}^{2}=\mathrm{CH}_{2} \mathrm{OH}, \mathrm{R}^{3}=\mathrm{C}(\mathrm{O})$} \\
\hline la & 0.0 & 0.0 & 0.0 \\
\hline Ib & -0.1 & 0.2 & 0.2 \\
\hline Ila & 8.0 & 7.6 & 7.7 \\
\hline Ilb & 7.9 & 7.9 & 8.0 \\
\hline
\end{tabular}

[a] Values derived by combining relative energies determined from single-point calculations at the MP2/aug-cc-pVDZ level and the free energy correction at the $M 062 X / 6-31 G(d)$ level are given in parenthesis.

M062X calculations were then performed to locate the transition states for the approach of reagent 4 in an exo mode to the two faces of ring $D$ in compounds 3. The endo approach would be prevented by the presence of the bulky TMS group. On the basis of the preceding conformational analysis, the $N_{\text {ind }}-\mathrm{H}$ indoloquinolizidine was modeled using conformation $\mathbf{I}$, whereas conformations la and lb were used for the $N_{\text {ind }}$-Boc derivative. Normal mode analysis confirmed the existence of a single imaginary frequency, which corresponds to the stretching of the carbon atoms involved in the forming bond between compounds $\mathbf{3}$ and $\mathbf{4}$ (denoted $C^{\mathbf{x}}$ and $C^{\mathbf{y}}$ hereafter; Figure 3 ).

Examination of the transition state structures showed that the distance between atoms $C^{\mathbf{x}}$ and $C^{\mathbf{y}}$ ranges between 1.94 and $2.01 \AA$, while they exhibit a certain degree of pyramidalization (between 23 and 30 degrees). The addition of reagent 4 at the $S i$ and $R e$ faces corresponds to an antiperiplanar arrangement, as shown by the fact that the $\mathrm{H}$ $\mathrm{C}^{\mathrm{x} \ldots} \mathrm{C}^{\mathbf{y}}-\mathrm{H}$ dihedral angle varies from 157 to 180 degrees. As expected, the largest deviations from the antiperiplanar 


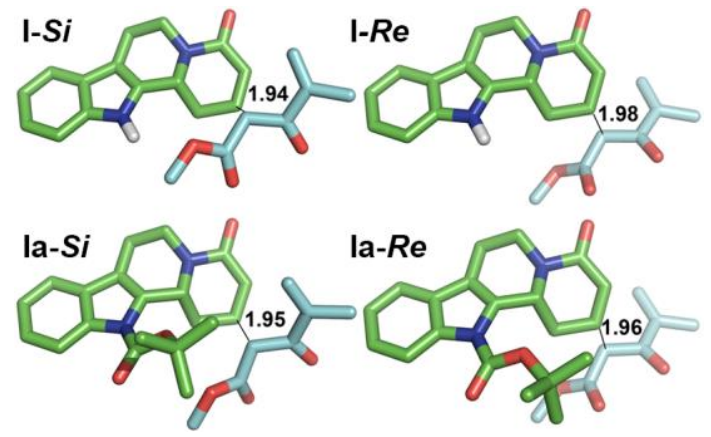

Figure 3. Representation of the most favored transition states for the exo approach of reagent 4 (blue sticks) to the $S i$ and $R e$ faces of the carboncarbon double bond in unsaturated $N_{\text {ind }}-\mathrm{H}$ indoloquinolizidines and their $N_{\text {ind }}{ }^{-}$ Boc derivatives (green sticks). The forming bond between carbon atoms $C^{\mathbf{x}}$ and $C^{y}$ is indicated by a black line (distance in $\AA$ ).

arrangement are found for the addition at the Si face of the carbon-carbon double bond in the $N_{\text {ind }}$-Boc indoloquinolizidine (167.1 and 157.3 degrees for la-Si and $\mathbf{l b}$ - $S i$, respectively), which reflects the steric hindrance originated from the Boc group.

The relative stability between the transition states is reported in Table 3. The results point out that addition of reagent 4 to the $N_{\text {ind }}-\mathrm{H}$ indoloquinolizidine in an exo mode is more favorable through the Si face of ring $\mathrm{D}$, thus leading to the formation of the $3-\mathrm{H} / 15-\mathrm{H}$ trans adduct, as expected from the usual stereoelectronic preference for an axial attack. Examination of the transition state I-Si reveals that the electrophilic terminal carbon atom of the Nazarov reagent is well positioned for the subsequent ring closure, although the length of the forming bond (3.26 A; Figure 4) suggests that the addition reaction occurs in a highly asynchronous process. In contrast, the most favorable transition state (la- $R e$ ) for the $N_{\text {ind }}$-Boc derivative corresponds to the $R e$ addition, leading to the $3-\mathrm{H} / 15-\mathrm{H}$ cis stereochemistry. This suggests that the steric hindrance of the bulky Boc group

Table 3. Relative free energy $(\mathrm{kcal} / \mathrm{mol})$ of the transition states of the $N_{\text {ind }^{-}}$ unsubstituted indoloquinolizidines and their $N_{\text {ind }}$-Boc derivatives.

\begin{tabular}{|c|c|c|c|}
\hline Conformation & Gas & THF & $\mathrm{CH}_{2} \mathrm{Cl}_{2}$ \\
\hline \multicolumn{4}{|c|}{$N_{\text {ind }}-\mathrm{H}, \mathrm{R}^{2}=\mathrm{R}^{3}=\mathrm{H}$} \\
\hline $\mathrm{I}-\mathrm{Si}$ & 0.0 & 0.0 & 0.0 \\
\hline $\mathrm{I}-\mathrm{Re}$ & 3.9 & 3.1 & 3.0 \\
\hline \multicolumn{4}{|c|}{$N_{\text {ind }}-\mathrm{H}, \mathrm{R}^{2}=\mathrm{H}, \mathrm{R}^{3}=\mathrm{C}(\mathrm{O}) \mathrm{OMe}$} \\
\hline $\mathrm{I}-\mathrm{Si}$ & 0.0 & 0.0 & 0.0 \\
\hline $\mathrm{I}-R e$ & 4.6 & 2.2 & 2.0 \\
\hline \multicolumn{4}{|c|}{$N_{\text {ind }}-$ Boc, $R^{2}=\mathrm{R}^{3}=\mathrm{H}$} \\
\hline la-Si & 4.4 & 3.5 & 3.3 \\
\hline la- $R e$ & 0.0 & 0.0 & 0.0 \\
\hline $\mathbf{l b}-S i$ & 5.7 & 4.3 & 3.9 \\
\hline $\mathrm{lb}-R e$ & 5.7 & 3.7 & 3.5 \\
\hline \multicolumn{4}{|c|}{$N_{\text {ind }}-\mathrm{Boc}, \mathrm{R}^{2}=\mathrm{H}, \mathrm{R}^{3}=\mathrm{C}(\mathrm{O}) \mathrm{OMe}$} \\
\hline la-Si & 3.8 & 3.6 & 3.5 \\
\hline la- $R e$ & 0.0 & 0.0 & 0.0 \\
\hline lb-Si & 4.6 & 3.6 & 3.3 \\
\hline $\mathrm{lb}-R e$ & 4.4 & 2.6 & 2.6 \\
\hline
\end{tabular}
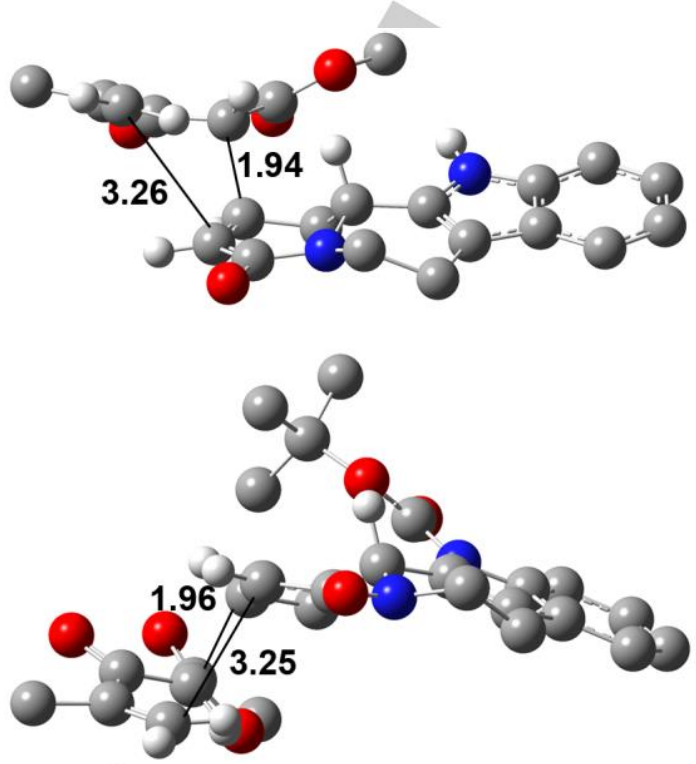

Figure 4. Representation of the transition states for the exo approach of reagent 4 to the $N_{\text {ind }}-\mathrm{H}$ indoloquinolizidine (I-Si; top) and its $N_{\text {ind }}$-Boc derivative (la-Re; bottom). Distances are in $\AA$. For the sake of clarity, a limited number of hydrogen atoms is shown.

overrides the stereochemical preference for the attack via the convex face of the $\alpha, \beta$-unsaturated lactam. On the other hand, the asynchronicity between addition of reagent 4 and ring closure is reflected in the distances between the intervening carbon atoms (Figure 4).

\section{Synthetic applications}

Once a straightforward procedure for the stereocontrolled construction of pentacyclic yohimbine-type derivatives had been developed, both in the racemic series and in enantiopure form, the usefulness and synthetic potential of the methodology was demonstrated by converting pentacycles $6 \mathrm{f}$ and $5 \mathrm{~h}$ to the allo and epiallo derivatives 13-16 (Scheme 4) and 19-21 (Scheme 5), respectively.

The structures 13-16 had been proposed for the indole alkaloids nitraraine, $\mathrm{O}$-acetylnitraraine, dihydronitraraine, and nitraraidine, respectively, isolated ${ }^{[35]}$ from Nitraria species, although they were shown to be incorrect by total synthesis. ${ }^{[36]}$

Stereoselective removal of the phenylsulfonyl group of $6 \mathbf{f}$ led to all-cis-pentacycle 11. Then, the enolizable ${ }^{[37]} \beta$-oxoester moiety of $\mathbf{1 1}$ was converted to an $\alpha, \beta$-unsaturated ester by palladium-catalyzed reductive coupling ${ }^{[38]}$ of the corresponding vinyl triflate. Finally, deprotection of the indole nitrogen of $\mathbf{1 2}$, followed by sequential reduction of the ester and lactam carbonyl groups, led to pentacyclic alcohol 13, which was acetylated to 14 . The synthesis of 15 , the putative structure of dihydronitraraine, was accomplished by deprotection of $\mathbf{1 2}$, followed by stereoselective catalytic hydrogenation and simultaneous reduction of the ester and lactam functions. Finally, 


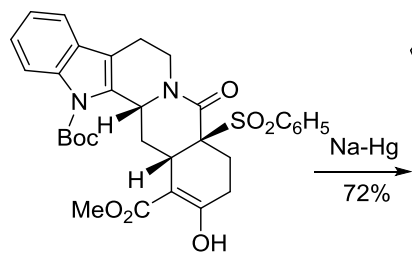

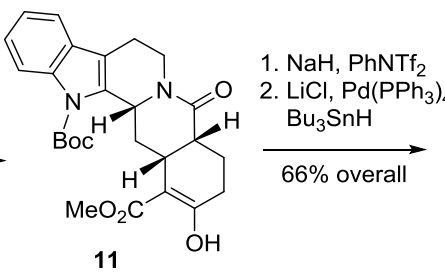

11<smiles>CC(=O)OC(C)=O</smiles>
2. DIBAL-H, 49\% overall 12
$\mathrm{ONa}, \mathrm{MeOH}$ $\mathrm{H}_{2}, \mathrm{Pd} / \mathrm{C}$ $\mathrm{LiAlH}_{4}$

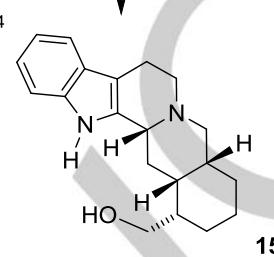

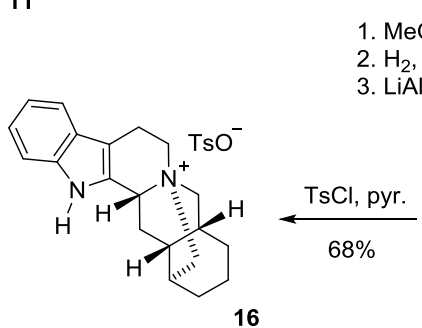

Scheme 4. Synthesis of the proposed structures of the alkaloids nitraraine (13), O-acetylnitraraine (14), dihydronitraraine (15), and nitraraidine (16).

treatment of alcohol 15 with tosyl chloride led to hexacyclic quaternary salt $\mathbf{1 6}$. The NMR data of $\mathbf{1 3}$ and $\mathbf{1 5}$ matched those reported in the literature for these compounds ${ }^{[36]}$ and, as expected, the melting point and ${ }^{1} \mathrm{H}$ NMR data of 13-16 were significantly different from those reported $^{[35]}$ for the natural products.

Taking into account that degradative and correlation studies of nitraraine alkaloids suggest that they embody a pentacyclic

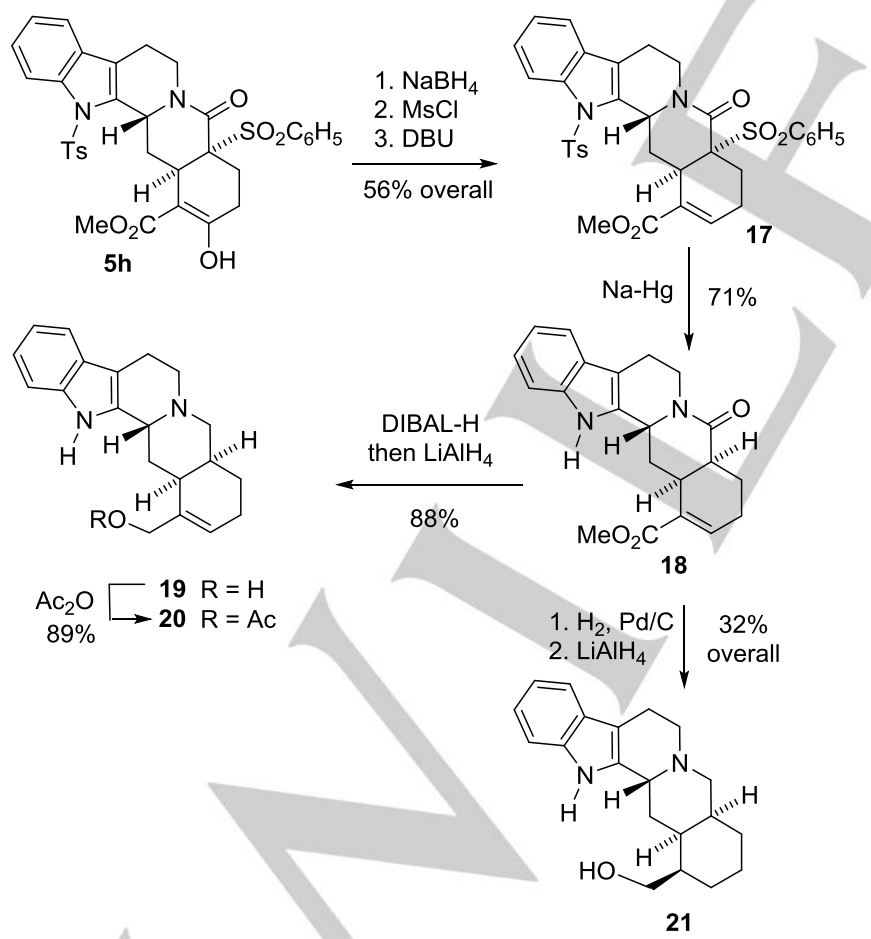

Scheme 5. Synthesis of epiallo derivatives 19-21. yohimbine-type skeleton, ${ }^{[35 a]}$ and having in hand a methodology that provides easy access to pentacyclic $3-\mathrm{H} / 15-\mathrm{H} / 20-\mathrm{H}$ trans/cis derivatives, we focused our efforts on the synthesis of the previously unreported epiallo compounds 19-21 with the hope of shedding light on the structure of these alkaloids.

In this series, pentacycle $5 \mathrm{~h}$ was converted to $\alpha, \beta$ unsaturated ester 17 by $\mathrm{NaBH}_{4}$ reduction, followed by mesylation of the resulting alcohol and base-promoted elimination (Scheme 5). A subsequent treatment of 17 with $\mathrm{Na}$ $\mathrm{Hg}$ brought about the stereoselective removal of the benzenesulfonyl group and the deprotection of the indole nitrogen, leading to pentacyclic lactam 18, which was converted to the target derivatives $19-21$ as in the above allo series. The melting point and ${ }^{1} \mathrm{H}$ NMR data of 19-21 were also different from those reported for nitraraine,$^{[35 a]} O$-acetylnitraraine $e^{[35 d]}$ and dihydronitraraine ${ }^{[35 \mathrm{~b}]}$ respectively, so the real structure of these alkaloids remains unknown. ${ }^{[39]}$

\section{Conclusions}

In summary, the silylated Nazarov reagent $\mathbf{4}$ is able to participate in base-promoted double Michael annulations with unsaturated indoloquinolizidine lactams bearing an additional activating group $\left(\mathrm{CO}_{2} \mathrm{Bn}\right.$ or $\left.\mathrm{SO}_{2} \mathrm{Ph}\right)$ at the carbonyl $\alpha$-position, allowing the straightforward construction of pentacyclic yohimbine-type systems.

Starting from $N_{\text {ind }}-\mathrm{H}$ or $N_{\text {ind }}-\mathrm{Ts}$ indoles, $3-\mathrm{H} / 15-\mathrm{H}$ trans pentacyclic derivatives $\mathbf{5}$ are stereoselectively formed. The presence of a tert-butoxycarbonyl group on the indole nitrogen induces a reversal of the facial selectivity, leading to $3-\mathrm{H} / 15-\mathrm{H}$ cis pentacycles. This result has been rationalized by means of theoretical calculations, which indicate that the preference for the $\mathrm{Si}$ facial selectivity found in $\mathrm{N}_{\text {ind }} \mathrm{H}$ indoloquinolizidines changes to $R e$ in their $N_{\text {ind }}$-Boc derivatives. Indeed, this effect can be attributed to the steric hindrance caused by the Boc 
moiety on the Si face of the most populated conformer of the indoloquinolizidine.

The presence or absence of a $\mathrm{CH}_{2} \mathrm{OH}$ (or $\mathrm{CH}_{2} \mathrm{OBoc}$ ) substituent at the indoloquinolizidine 6 position does not modify the stereochemical outcome of the annulation. Either $\mathrm{Cs}_{2} \mathrm{CO}_{3}$ or DBU can be used as bases to promote stereoselective annulations, although DBU is the base of choice when the substrate is an $N_{\text {ind }}-\mathrm{Boc}$ lactam bearing a $\mathrm{SO}_{2} \mathrm{Ph}$ electronwithdrawing group.

The activating phenylsulfonyl substituent in the pentacyclic adducts 5 or $\mathbf{6}$ can be stereoselectively removed, leading to 3$\mathrm{H} / 15-\mathrm{H} / 20-\mathrm{H}$ trans-cis or cis-cis derivatives, respectively, thus opening stereodivergent routes to epiallo and allo yohimbinetype targets.

\section{Experimental Section}

General procedure for the double Michael addition reactions. Method A. A solution of unsaturated indolo[2,3-a]quinolizidine lactam 3 (1 equiv.) in anhydrous $\mathrm{CH}_{2} \mathrm{Cl}_{2}$ was added at $0{ }^{\circ} \mathrm{C}$ under an inert atmosphere to a solution of the Nazarov reagent 4 (3 equiv.) and $\mathrm{Cs}_{2} \mathrm{CO}_{3}$ (6 equiv.) in anhydrous $\mathrm{CH}_{2} \mathrm{Cl}_{2}(5 \mathrm{mM})$, and the mixture was allowed to warm slowly to room temperature. After $20 \mathrm{~h}$ of stirring at room temperature, the mixture was concentrated under reduced pressure. Flash chromatography (9:1 hexane-EtOAc) of the resulting oil afforded compounds 5 and 6 (Table 1, entries 1, 2, 3, 5, 7, 9, 11, and 12) as pale yellow foams.

Method B. A solution of unsaturated indolo[2,3-a]quinolizidine lactam 3 ( 1 equiv.) in anhydrous THF was added at $0{ }^{\circ} \mathrm{C}$ under an inert atmosphere to a solution of the Nazarov reagent 4 (2 equiv.) and DBU (1 equiv.) in anhydrous THF ( $0.1 \mathrm{M})$, and the mixture was allowed to warm slowly to room temperature. After $20 \mathrm{~h}$ of stirring at room temperature, the mixture was quenched with $\mathrm{H}_{2} \mathrm{O}$ and extracted with EtOAc. The combined organic extracts were washed with brine, dried over anhydrous $\mathrm{MgSO}_{4}$, filtered, and concentrated under reduced pressure. Flash chromatography (9:1 hexane-EtOAc) afforded the corresponding adducts 5 and 6 (Table 1, entries 4, 6, 8, and 10) as pale yellow foams.

General procedure for the removal of the phenylsulfonyl group. $\mathrm{Na}_{2} \mathrm{HPO}_{4}$ (50 equiv.) and sodium amalgam (25 equiv.) were added to a solution of the phenylsulfonyl derivative $5 \mathbf{e}, \mathbf{6 e}, \mathbf{6 f}$, or $\mathbf{1 7}$ (1 equiv.) in anhydrous methanol $(0.02 \mathrm{M})$ at $-78{ }^{\circ} \mathrm{C}$, and the mixture was stirred for 2-5 hours. The solution was then filtered and quenched with $\mathrm{H}_{2} \mathrm{O}$ at $0 \stackrel{\circ}{\circ} \mathrm{C}$. The methanol was evaporated, and the aqueous layer was extracted with EtOAc. The combined organic extracts were dried over anhydrous $\mathrm{MgSO}_{4}$, filtered, and concentrated under reduced pressure. Flash chromatography (9:1 hexane-EtOAc) afforded compounds 10 (65\%), 8 $(74 \%), 11(72 \%)$, or $18(71 \%)$, respectively.

Conversion of the enolizable $\beta$-oxoester moiety to an $\alpha, \beta$ unsaturated ester.

Method A. First step: NaH (1.2 equiv.) was added at room temperature to a solution of $\beta$-oxoester 11 (1 equiv.) in $\operatorname{DME}(0.4 \mathrm{M})$, and the mixture was stirred at it for $3 \mathrm{~h}$. $\mathrm{PhNTf}_{2}$ (1equiv.) was added in one portion and, after stirring for $2 \mathrm{~h}$, the mixture was poured into saturated aqueous $\mathrm{NH}_{4} \mathrm{Cl}$ and extracted with $\mathrm{Et}_{2} \mathrm{O}$. The combined organic extracts were washed with brine, dried, filtered, and concentrated under an reduced pressure. The resulting residue was chromatographed (9:1 hexane$\mathrm{EtOAc}$ ) to afford the corresponding vinyl triflate. Second step: $\mathrm{Bu}_{3} \mathrm{SnH}$ (1.2 equiv.) was added dropwise over 20 minutes, at $\mathrm{rt}$ under inert atmosphere, to a solution of the above vinyl triflate (1 equiv.), LiCl (3 equiv.), and $\mathrm{Pd}\left(\mathrm{PPh}_{3}\right)_{4}(0.02$ equiv.) in $\operatorname{THF}(0.3 \mathrm{M})$, and the resulting mixture was stirred at $50{ }^{\circ} \mathrm{C}$ for $3 \mathrm{~h}$. After cooling, $\mathrm{Et}_{2} \mathrm{O}$ was added, and the resulting solution was washed with $10 \% \mathrm{KF}$ and brine, dried, filtered, and concentrated under reduced pressure. Flash chromatography (9:1 hexane-EtOAc) of the residue afforded unsaturated ester 12 (66\%).

Method B. First step: $\mathrm{NaBH}_{4}(35 \mathrm{mg}, 0.8 \mathrm{mmol})$ was added in small portions to a solution of compound $5 \mathbf{h}(160 \mathrm{mg}, 0.24 \mathrm{mmol})$ in THF$\mathrm{MeOH}(50: 1,3.5 \mathrm{~mL})$ at $0{ }^{\circ} \mathrm{C}$. After the mixture was stirred overnight at $0{ }^{\circ} \mathrm{C}$, saturated aqueous $\mathrm{NaHCO}_{3}$ was added, and the aqueous solution was extracted with EtOAc. The combined organic extracts were dried, filtered, and concentrated under reduced pressure. Flash chromatography (9:1 hexane-EtOAc) of the residue afforded the corresponding alcohol. Second step: DMAP (4 mg, $0.03 \mathrm{mmol}, \mathrm{Et}_{3} \mathrm{~N}$ $(105 \mu \mathrm{L}, 0.76 \mathrm{mmol})$ and $\mathrm{MsCl}(35 \mu \mathrm{L}, 0.45 \mathrm{mmol})$ were added at $0{ }^{\circ} \mathrm{C}$ to a solution of the mixture of alcohols in $\mathrm{CH}_{2} \mathrm{Cl}_{2}(5 \mathrm{~mL})$. The mixture was stirred at $0{ }^{\circ} \mathrm{C}$ for 10 minutes and at room temperature for $4 \mathrm{~h}$. Water $(5$ $\mathrm{mL}$ ) was added, and the aqueous solution was extracted with $\mathrm{CH}_{2} \mathrm{Cl}_{2}$. The combined organic extracts were dried and filtered, and the solvent was evaporated at reduced pressure to afford a mixture of diastereomeric mesylates. Third step: DBU $(112 \mu \mathrm{L}, 0.75 \mathrm{mmol})$ was added to a solution of the above mesylates in dry benzene $(5 \mathrm{~mL})$, and the resulting solution was stirred at $80 \stackrel{\circ}{\circ} \mathrm{C}$ for $6 \mathrm{~h}$. The solvent was evaporated, and the residue was purified by flash chromatography (1:9 hexane-EtOAc) to afford unsaturated ester 17 (87 mg, 56\% yield).

General procedure for the removal of the tert-butoxycarbonyl group. Sodium methoxide ( 15 equiv.) was added to a solution of the $N_{\text {ind }}$-Boc derivatives ( 1 equiv.) in dry $\mathrm{MeOH}(0.004 \mathrm{M})$. The resulting mixture was stirred overnight at reflux temperature. Then, saturated aqueous $\mathrm{NH}_{4} \mathrm{Cl}$ was added, the $\mathrm{MeOH}$ was removed under reduced pressure, and the aqueous layer was extracted with $\mathrm{CH}_{2} \mathrm{Cl}_{2}$. The combined organic extracts were dried, filtered, and concentrated under reduced pressure. The residue was purified by flash chromatography (9:1 hexane-EtOAc) to afford the corresponding $N_{\text {ind }}-\mathrm{H}$ derivatives.

Computational methods. Full geometry optimizations were performed with the M062X $X^{[31]}$ density functional method by using the $6-31 \mathrm{G}(\mathrm{d})^{[32]}$ basis set. Solvent effects were accounted for by means of single-point calculations performed at the B3LYP/6-31G(d) ${ }^{[33]}$ and M062X/6-31G(d) level in conjunction with the SMD version of the IEFPCM model. ${ }^{[34]}$ The nature of the stationary points was verified by inspection of the vibrational frequencies within the harmonic oscillator approximation. The relative free energies were estimated by combining the free energy differences in the gas phase (at $1 \mathrm{~atm}$. and $298.15 \mathrm{~K}$ ), obtained by using the rigid rotorharmonic oscillator model as implemented in Gaussian 09, ${ }^{[40]}$ with the solvation free energies determined with the SMD model. The suitability of this computational scheme is supported from the results determined for 
similar reactive processes. ${ }^{[41]}$ Calculations were performed by using Gaussian 09.

\section{Acknowledgements}

Financial support from the Spanish Ministry of Economy and Competitiveness (MINECO; Projects CTQ2012-35250 and SAF2014-57094-R) and the Generalitat de Catalunya (2014SGR0155 and 2014SGR1189) is gratefully acknowledged. Thanks are also due to the MINECO for fellowships to $F$. A. (AP2010-1663) and C. E. (FPDI-2013-15572), the support from Icrea Academia to F. J. L., and the Leonardo da Vinci programme (Unipharma-Graduates 9) for a mobility grant to C.A. The Consorci de Serveis Universitaris de Catalunya (CSUC) is acknowledged for the computational facilities.

Keywords: Alkaloids - Density-functional calculations - Michael reaction $\cdot$ Stereoselectivity $\cdot$ Nazarov reagent.

[1] a) R. T. Brown in Monoterpenoid Indole Alkaloids, Vol. 25, Part 4 (Ed. J. E. Saxton) in The Chemistry of Heterocyclic Compounds, (Eds.: A Weissberger, E. C. Taylor) John Wiley and Sons, Chichester, 1983, pp. 63-146; b) M. Lounasmaa, A. Tolvanen in Monoterpenoid Indole Alkaloids, Supplement to Vol. 25, Part 4 (Ed.: J. E. Saxton) in The Chemistry of Heterocyclic Compounds, (Ed.: E. C. Taylor) John Wiley and Sons, Chichester, 1994, pp. 57-159.

[2] a) R. T. Brown in Monoterpenoid Indole Alkaloids, Vol. 25, Part 4 (Ed.: J. E. Saxton) in The Chemistry of Heterocyclic Compounds, (Eds.: A Weissberger, E. C. Taylor) John Wiley and Sons, Chichester, 1983, pp. 147-200; b) C. Szántay, K. Honty in Monoterpenoid Indole Alkaloids, Supplement to Vol. 25, Part 4 (Ed.: J. E. Saxton) in The Chemistry of Heterocyclic Compounds, (Ed.: E. C. Taylor) John Wiley and Sons, Chichester, 1994, pp. 161-216.

[3] Biogenetic numbering: J. Le Men, W. I. Taylor, Experimentia 1965, 21, 508-510.

[4] Normal (3- $\mathrm{H} / 15-\mathrm{H}$ cis, $15-\mathrm{H} / 20-\mathrm{H}$ trans), pseudo (trans, trans), allo (cis, cis), and epiallo (trans, cis).

[5] a) S. M. Allin, J. S. Khera, C. I. Thomas, J. Witherington, K. Doyle, M. R. J. Elsegood, M. Edgar, Tetrahedron Lett. 2006, 47, 1961-1964; b) S. M. Allin, J. S. Khera, J. Witherington, M. R. J. Elsegood, Tetrahedron Lett. 2006, 47, 5737-5739.

[6] A. Deiters, M. Pettersson, S. F. Martin, J. Org. Chem. 2006, 71, 65476561.

[7] T. Naito, O. Miyata, I. Ninomiya, Heterocycles 1987, 26, 1739-1742.

[8] L. E. Overman, A. J. Robichaud, J. Am. Chem. Soc. 1989, 111, 300308.

[9] S. Peng, E. Winterfeldt, Liebigs Ann. Chem. 1990, 319-322.

[10] D. Gomez-Pardo, D. Desmaële, J. d'Angelo, Tetrahedron Lett. 1992, 33, 6633-6636.

[11] J. Ficini, A. Guingant, J. d'Angelo, J. Am. Chem. Soc. 1979, 101, 13181319.

[12] The same $3-\mathrm{H} / 15-\mathrm{H}$ trans relationship resulted in the Diels-Alder cycloaddition between an $N_{\text {ind }}$-tosyl indoloquinolizidine lactam and 2 (trimethylsilyloxy)butadiene: D. Gomez-Pardo, J. d'Angelo, Tetrahedron Lett. 1992, 33, 6637-6640.

[13] a) P. Deslongchamps, Stereoelectronic Effects in Organic Chemistry; Pergamon Press: Oxford, 1983, p 221; b) P. Perlmutter, Conjugate Addition Reactions in Organic Synthesis; Pergamon Press: Oxford, 1992, p 25.
[14] The same trans stereoselectivity was also observed in kinetically controlled conjugate addition reactions on $11 \mathrm{~b}$-unsubstituted, unsaturated benzo[a]quinolizidine lactams using 6,7-dimethoxy-1methyl-3,4-dihydroisoquinoline,${ }^{[14 a]} 2$-lithio- $N, N$-dimethylacetamide, ${ }^{[14 b]}$ a vinyl cuprate,$^{[14 c]}$ or sulfur-stabilized anions ${ }^{[14 d]}$ as nucleophiles: a) $\mathrm{T}$. Kametani, S. A. Surgenor, K. Fukumoto, J. Chem. Soc., Perkin Trans. 1, 1981, 920-925; b) T. Naito, N. Kojima, O. Miyata, I. Ninomiya, Chem. Pharm. Bull. 1986, 34, 3530-3533; c) S. M. Allin, L. J. Duffi, P. C Bulman Page, V. McKee, M. Edgar, M. J. Mckenzie, M. Amat, O. Bassas, M. M. M. Santos, J. Bosch, Tetrahedron Lett. 2006, 47, 5713 5716; d) E. García, E. Lete, N. Sotomayor J. Org. Chem. 2006, 71, 6776-6784.

[15] M. Amat, F. Arioli, M. Pérez, E. Molins, J. Bosch, Org. Lett. 2013, 15, 2470-2473.

[16] a) The original Nazarov reagent was first reported by: I. N. Nazarov, S. I. Zavyalov, Zh. Obshch. Khim. 1953, 23, 1703. Engl. Transl. 1953, 23, 1793. Chem. Abstr. 1954, 48, 13667h; for reviews, see: b) R. Zibuck in Encyclopedia of Reagents for Organic Synthesis (Ed.: L. A. Paquette), Wiley, Chichester, 1995; Vol. 5, pp 3558-3559; c) G. Audran, P. Brémond, M. Feuerstein, S. R. A. Marque, M. Santelli Tetrahedron 2013, 69, 8325-8348.

[17] J.-F. Lavallée, P. Deslongchamps, Tetrahedron Lett. 1988, 29, 51175118.

[18] Lactams $\mathbf{3 c}$ and $\mathbf{3 g}$ were prepared by deprotection (TFA) of the corresponding $N_{\text {ind }}$-Boc derivatives $\mathbf{3 d}$ and $\mathbf{3 f}$, respectively

[19] a) Lactam 3d was prepared (72\% overall yield) from indolo[2,3a]quinolizidin-4-one (7) ${ }^{[19 \mathrm{~b}]}$ [i) $\mathrm{Boc}_{2} \mathrm{O}$; ii) $\mathrm{ClCO}_{2} \mathrm{Bn}$, LiHMDS, then $\mathrm{CISeC}_{6} \mathrm{H}_{5}$; iii) $\mathrm{H}_{2} \mathrm{O}_{2}$, pyr]; b) I. T. Raheem, P. S. Thiara, E. A. Peterson, E. N. Jacobsen, J. Am. Chem. Soc. 2007,129,13404-13405.

[20] For DBU-promoted stereoselective annulation reactions with the original Nazarov reagent, see: C.-H. Tu, Y.-K. Wu, K.-S. Shia, S.-C Kuo, H.-J. Liu, M.-T. Hsieh, Synlett 2014, 25, 543-546.

[21] The resulting cis $\mathrm{D} / \mathrm{E}$ ring junction arises from stereoelectronic control: G. Berthiaume, J.-F. Lavallée, P. Deslongchamps, Tetrahedron Lett. 1986, 27, 5451-5454.

[22] An alternative mechanism involving a concerted Diels-Alder reaction of the dienolate has also been proposed. For a discussion of mechanistic aspects of double Michael addition reactions of Nazarov reagents with 2-(ethoxycarbonyl)-2-cyclohexenones, see: a) J.-F. Lavalleé, C. Spino, R. Ruel, K. T. Hogan, P. Deslongchamps, Can. J. Chem. 1992, 70, 1406-1426; b) T. Tricotet, R. Brückner, Tetrahedron Lett. 2006, 47, 8499-8502.

[23] a) J. E. Ellis, J. S. Dutcher, C. H. Heathcock, Synth. Commun. 1974, 4, 71-77; b) Y. Hoashi, T. Yabuta, P. Yuan, H. Miyabe, Y. Takemoto, Tetrahedron 2006, 62, 365-374; c) S. Benetti, S. Carlo, C. De Risi, G. P Pollini, A. C. Veronese, V. Zanirato, Synlett 2008, 2609-2612. See also references [16b] and [20].

[24] Typically, 2-(alkoxycarbonyl)-2-cyclohexenone derivatives have been used in these reactions: T. Tricotet, R. Brückner, Eur. J. Org. Chem. 2007, 1069-1074. See also references [17] and [22]

[25] $\quad \alpha, \beta$-Unsaturated lactams are poor Michael acceptors: a) $H$. Nagashima, N. Ozaki, M. Washiyama, K. Itoh, Tetrahedron Lett. 1985, 26, 657-660 b) T. J. Hagen, Synlett 1990, 63-66. See also references [6] and [8].

[26] For the stereoselective removal of a phenylsulfonyl group placed at the $\alpha$-position of a lactam carbonyl, see: Y. C. Jung, C. H. Yoon, E. Turos K. S. Yoo, K. W. Jung, J. Org. Chem. 2007, 72, 10114-10122.

[27] Somewhat surprisingly, when the reaction was performed at a higher concentration ( $0.1 \mathrm{M}$ instead of the usual concentration $0.005 \mathrm{M})$, the ratio of $3-\mathrm{H} / 15-\mathrm{H}$ cis/trans isomers changed to $1: 2$. The erratic facial selectivity in the $\mathrm{Cs}_{2} \mathrm{CO}_{3}$-promoted annulations with $N_{\text {ind }}$-Boc lactams bearing the phenylsulfonyl activating group and its variation with the concentration could be attributed to coordination effects between the cesium and the sulfonyl group.

[28] Lactam $3 \mathbf{f}$ was prepared (61\% overall yield) as a racemate from $7^{[19 b]}$ [i) $\mathrm{Boc}_{2} \mathrm{O}$; ii) $\mathrm{PhSSO}_{2} \mathrm{Ph}$, LiHMDS; iii) $m$-CPBA]. 
[29] Lactam 3h was prepared (38\% overall yield) from $7^{[19 b]}$ [i) $\mathrm{TsCl}, \mathrm{NaH}$; ii) $\mathrm{PhSSO}_{2} \mathrm{Ph}$, LiHMDS; iii) $m$-CPBA].

[30] a) S. M. Allin, C.I. Thomas, J. E. Allard, K. Doyle, M. R. J. Elsegood, Tetrahedron Lett. 2004, 45, 7103-7105; b) M. Amat, A. Gómez-Esqué, C. Escolano, M. M. M. Santos, E. Molins, J. Bosch, J. Org. Chem. 2009 74, 1205-1211; c) M. Amat, C. Ramos, M. Pérez, E. Molins, P. Florindo, J. Bosch, Chem. Commun. 2013, 49, 1954-1956. See also ref [5]

[31] Y. Zhao, D. G. Truhlar, Theor. Chem. Acc. 2008, 120, 215-241.

[32] P. C. Hariharan, J. A. Pople, Theor. Chim. Acta, 1973, 28, 213-218.

[33] a) A. D. Becke, J. Chem. Phys., 1993, 98, 5648-5652; b) C. Lee, W Yang, R. G. Parr, Phys. Rev. B: Condens. Matter, 1988, 37, 785-789.

[34] A. V. Marenich, C. J. Cramer, D. G. Truhlar, J. Phys. Chem. B 2009 113, 6378-6396.

[35] a) A. A. Ibragimov, S. Y. Yunusov, Chem. Nat. Compd. 1985, 21, 502 509; b) A. A. Ibragimov, S. Y. Yunusov, Chem. Nat. Compd. 1985, 21 510-512; c) T. S. Tulyaganov, F. Kh. Allaberdiev, Chem. Nat. Compd. 2002, 38, 602-604; d) T. S. Tulyaganov, N. M. Kozimova, Chem. Nat Compd. 2005, $41,578-579$.

[36] a) S. Takano, K. Samizu, T. Sugihara, S. Satoh, K. Ogasawara, Chem. Lett. 1989, 1777-1780; b) R. Yamaguchi, T. Hamasaki, T. Sasaki, T. Ohta, K. Utimoto, S. Kozima, H. Takaya, J. Org. Chem. 1993, 58, 11361143; c) E. Päiviö, M. Berner, A. Tolvanen, R. Jokela, Heterocycles 2000, 53, 2241-2246; d) H. Sakagami, K. Ogasawara, Heterocycles 2001, 54, 43-47.

[37] Yohimbine-type systems with a cis-D/E ring junction are predominantly enolic in solution: a) L. D. Albright, L. Goldman, J. Org. Chem. 1965 30, 1107-1110; b) F. V. Brutcher, W. D. Vanderwerff, B. Dreikorn, J Org. Chem. 1972, 37, 297-301.

[38] W. J. Scott, J. K. Stille, J. Am. Chem. Soc. 1986, 108, 3033-3044.
[39] a) R. Salame, E. Gravel, E. Poupon, Tetrahedron Lett. 2011, 52, 6453 6456; b) F. Arioli, M. Pérez, F. Subrizi, N. Llor, J. Bosch, M. Amat, J. Org. Chem. 2014, 79, 7740-7745.

[40] Gaussian 09, Revision C.01, M. J. Frisch, G. W. Trucks, H. B. Schlegel, G. E. Scuseria, M. A. Robb, J. R. Cheeseman, G. Scalmani, V. Barone B. Mennucci, G. A. Petersson, H. Nakatsuji, M. Caricato, X. Li, H. P. Hratchian, A. F. Izmaylov, J. Bloino, G. Zheng, J. L. Sonnenberg, M. Hada, M. Ehara, K. Toyota, R. Fukuda, J. Hasegawa, M. Ishida, T. Nakajima, Y. Honda, O. Kitao, H. Nakai, T. Vreven, J. A. Montgomery, Jr., J. E. Peralta, F. Ogliaro, M. Bearpark, J. J. Heyd, E. Brothers, K. N. Kudin, V. N. Staroverov, T. Keith, R. Kobayashi, J. Normand, K. Raghavachari, A. Rendell, J. C. Burant, S. S. Iyengar, J. Tomasi, M. Cossi, N. Rega, N. J. Millam, M. Klene, J. E. Knox, J. B. Cross, V. Bakken, C. Adamo, J. Jaramillo, R. Gomperts, R. E. Stratmann, O. Yazyev, A. J. Austin, R. Cammi, C. Pomelli, J. W. Ochterski, R. L. Martin, K. Morokuma, V. G. Zakrzewski, G. A. Voth, P. Salvador, J. J. Dannenberg, S. Dapprich, A. D. Daniels, O. Farkas, J. B. Foresman, J. V. Ortiz, J. Cioslowski, D. J. Fox, Gaussian, Inc., Wallingford CT, 2010.

[41] a) L. R. Domingo, Tetrahedron 2002, 58, 3765-3774; b) S. Schenker, C. Schneider, S. B. Tsogoeva, T. Clark, J. Chem. Theory Comput. 2011, 7, 3586-3595; c) H. V. Pham, D. B. C. Martin, C. D. Vandewal, K. N. Houk, Chem. Sci. 2012, 3, 1650-1655; d) M. Linder, A. J. Johannson, T. Brinch, Org. Lett. 2012, 14, 118-121; e) M. Linder, A. J. Johannson, T. Brinch, J. Org. Chem. 2012, 77, 6563-6573; f) S. Llabrés, E. VicenteGarcía, S. Preciado, C. Guiu, R. Pouplana, R. Lavilla, F. J. Luque, Chem. Eur. J. 2013, 19, 13355-13361. 
Entry for the Table of Contents (Please choose one layout)

Layout 1:

\section{FULL PAPER}

Text for Table of Contents

((Insert TOC Graphic here: max. width: $5.5 \mathrm{~cm}$; max. height: $5.0 \mathrm{~cm})$ )

Layout 2:

\section{FULL PAPER}

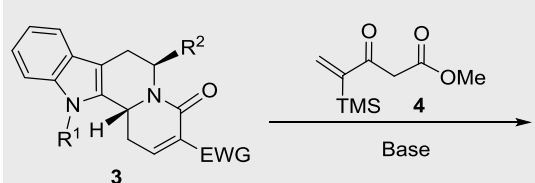

$\mathrm{R}^{1}=\mathrm{H}$ or Boc $\mathrm{R}^{2}=\mathrm{H}$ or $\mathrm{CH}_{2} \mathrm{OBoc}$

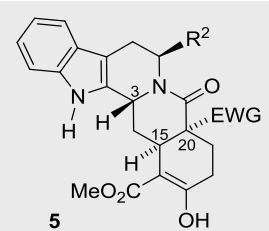

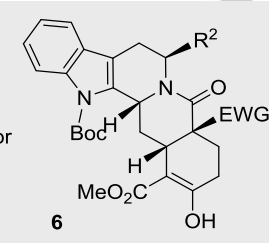

6
Author(s), Corresponding Author(s)*

Page No. - Page No.

Title

The stereocontrolled formation of pentacyclic 3- $\mathrm{H} / 15-\mathrm{H} / 20-\mathrm{H}$ trans-cis (5) or cis-cis (6) derivatives by double Michael addition of the silylated Nazarov reagent 4 to lactams $\mathbf{3}$ is reported. The reversal of the facial selectivity caused by the Boc group is rationalized by means of theoretical calculations. The stereoselective removal of the $\mathrm{C}-20 \mathrm{SO}_{2} \mathrm{Ph}$ electron-withdrawing group opens access to epiallo and allo yohimbine-type targets. 